\title{
EFFECT OF RAMAdAN INTERMitTENT FASTING ON Aerobic and Anaerobic Performance and Perception of Fatigue in Male Elite Judo Athletes
}

\author{
Anis Chaouachi, ${ }^{1,5}$ Aaron J. Coutts, ${ }^{2}$ Karim Chamari, ${ }^{1}$ Del P. Wong, ${ }^{3}$ Mustapha Chaouachi, ${ }^{1}$ \\ Moktar Chtara, ${ }^{1}$ Rachida Roky, ${ }^{4}$ ANd Mohamed Amri ${ }^{5}$ \\ ${ }^{1}$ Research Unit "Evaluation, Sport, Health," National Center of Medicine and Science in Sports (CNMSS), Tunis, Tunisia; \\ ${ }^{2}$ School of Leisure, Sport and Tourism, University of Technology, Sydney; ${ }^{3}$ Department of Health and Physical Education, Hong \\ Kong Institute of Education, Hong Kong, China; ${ }^{4}$ Laboratory of Physiology and Molecular Genetics, Faculty of Science, \\ Ain Chock, Casablanca, Morocco; and ${ }^{5}$ Laboratory of Functional Neurophysiology and Pathology, Faculty of Sciences \\ Tunis, Tunis, Tunisia
}

\begin{abstract}
Chaouachi, A, Coutts, AJ, Chamari, K, Wong, DP, Chaouachi, M, Chtara, M, Roky, R, and Amri, M. Effect of ramadan intermittent fasting on aerobic and anaerobic performance and perception of fatigue in male elite judo athletes. $J$ Strength Cond Res 23(9): 2702-2709, 2009-The aim of the present study was to evaluate the influence of the Ramadan intermittent fast (RIF) on aerobic and anaerobic exercise performance in elite judo athletes (Judokas) maintaining their usual training loads. Physical performance tests (squat jump [SJ]), countermovement jump [CMJ], 30-second repeated jump, 30-m sprint, and the multistage fitness test) and fatigue scores were measured in 15 elite Judokas on 4 occasions: before Ramadan (T1), at the beginning of Ramadan (T2), at the end of Ramadan (T3) and 3 weeks after Ramadan. Results showed that 30-m sprint performance, multistage shuttle run test, $\mathrm{SJ}$, and CMJ did not change during Ramadan. However, average power during the 30-second repeated jump test was slightly lower at the end of Ramadan $(22.4 \pm 2.3 \mathrm{~W} / \mathrm{kg} ; P<0.05)$ than before Ramadan $(23.4 \pm 2.3 \mathrm{~W} / \mathrm{kg})$. There was a minor reduction of $1.3 \mathrm{~kg}$ in body mass and an increase in total fatigue scores (T2, $19 \pm 5$; T3, $16 \pm 4$; both $P<0.05)$ during Ramadan in comparison with the control period (T1, $12 \pm 3$ ). These results show that the RIF has little effect on aerobic performance and on very short duration sprinting and jumping test performance in elite Judokas. Additionally, experienced athletes can maintain both sufficient energy intake and normal training loads during the RIF. The slight reduction in the 30 -second jump test may be
\end{abstract}

Address correspondence to Anis Chaouachi, anis.chaouachi@email.ati.tn. 23(9)/2702-2709

Journal of Strength and Conditioning Research

(C) 2009 National Strength and Conditioning Association associated with reduced central drive and body mass. Collectively, these results suggest that the RIF has little effect on the performance of experienced Judokas, but Muslim athletes who train during the RIF should carefully periodize their training load and monitor their food intake and fatigue levels to avoid performance decrements.

KEY WoRDS Islamic fasting, sports, exercise, nutrition

\section{INTRODUCTION}

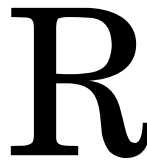
amadan is a fundamental rule of Islam and commands that healthy adult Muslims must refrain from eating, drinking, smoking, and having sexual relations from sunrise to sunset during the month of Ramadan. Although there are no restrictions on the quantity or type of food that can be consumed during the night with the Ramadan intermittent fast (RIF), several behavioral changes, such as the number and timing of daily meals and a reduction in sleeping hours, are observed (20,31). However, previous studies have shown that the RIF can influence substrate availability and utilization $(4,13)$ and induce acute diurnal dehydration (25). Collectively these changes may cause physiological and psychological perturbations that can have detrimental effects on sports performance. At present, however, there are few studies that have investigated the effects of RIF on the health and performance of highly trained athletes undertaking arduous training regimens $(4,7,23,29,34)$.

Judo is a sport characterized by brief bouts of high-intensity, intermittent exercise that requires energy provision through both aerobic and anaerobic pathways (11). Previous studies have shown that well-developed aerobic and anaerobic power are important factors in judo $(11,12)$ and that both of these capacities are influenced by diet and substrate availability (28). A common difficulty for elite athletes living in

2702 Journal of Strength and Conditioning Research 
Journal of Strength and Conditioning Research" | www.nsca-jscr.org

Muslim countries is that training and competition are often scheduled during Ramadan, which may affect their diet and substrate availability. Indeed, there is a general perception among athletes, coaches, and physicians that athletes undergoing Ramadan fasting have difficulty in maintaining their training loads, body mass, and physical work capacity. Although previous research has shown that experimental fasting prior to exercise reduces time to fatigue in humans (26), at present it is unknown if the RIF has the same negative affects on physical performance in elite judo athletes (Judokas).

Therefore, a large study was undertaken to evaluate the influence of RIF on maximal exercise performance, perception of fatigue, circulating lipid profile markers, inflammatory and immunological profile markers, and body composition during Ramadan in elite Judokas undertaking their usual training loads. The aim of the present paper is to report on the exercise performance and perception of fatigue parameters of that study.

\section{Methods}

\section{Experimental Approach to the Problem}

There is limited information on the influence of the RIF on physiological and performance changes in the applied sports training setting. Therefore, the present study was designed to determine whether the RIF would affect exercise performance compared with the levels measured before and after Ramadan in a selected group of male elite Judoka who were maintaining their training loads. To achieve this, a semilongitudinal study with repeated-measures design was used to determine the change in aerobic and anaerobic performance tests and perception of fatigue on 4 separate occasions. The performance tests used in this study were selected because they are common tests for evaluating Judo athletes and provide a comprehensive evaluation of physical performance of Judo athletes. In accordance with recent research $(23,29)$, it was hypothesized that the RIF would be associated with reduced aerobic power but not anaerobic performance.

\section{Subjects}

Fifteen healthy male elite judo athletes belonging to the Tunisian junior national judo team volunteered to participate in this study, which took place from October to December 2005. All participants had a minimum of 8 years of competitive experience in regional and national tournaments, and 10 of them had competed at the international level (international tournaments, Arabic, Maghreb, African championship, and world junior championships). Their skill level according to the Japanese grade system was black belt of various ranks (dan). Subjects represented various weight classes: 6 competed in the under- $60 \mathrm{~kg}$ class (U-60), 5 in the $\mathrm{U}-66,2$ in the U-73, and 2 in the U-81. At the time of the study, these athletes were among the best Judokas of their age and weight category in Tunisia based on their achievements and performance in national and/or international championships and most of them had won medals at prior competition events. All subjects followed Islam devoutly, were nonsmokers, and did not consume alcohol. The mean and standard deviation for their age, body mass $(\mathrm{BM})$, and body mass index $(\mathrm{BMI})$ were $18 \pm 1$ years, $68.13 \pm 8.24 \mathrm{~kg}$, and $22.4 \pm 1.8 \mathrm{~kg} / \mathrm{m}^{-2}$, respectively.

At the time of the study, all Judokas trained and lived together at the Tunisian High School Sports Centre, Tunis, where the best national-level athletes are accommodated in training camps for their individual sports prior to competition. All the Judokas were regularly exercising to maintain their physical performance and body mass by undertaking their usual training loads, supervised by their coaches, and were preparing for the upcoming national and international competitions. Both the training volume and intensity were relatively high; the weekly training program included 9 training sessions averaging a total of 17 hours ( 6 days/week and $\geq 2$ hours/day). Their regular judo training consisted mainly of a repetitive series of short and intense exercises involving various components within a judo session; judospecific interval training, technique; and/or situation-specific drills; and Randori (free-style sparring) (30). Some additional cardiovascular training and fundamental resistance training were incorporated within these sessions.

Prior to commencing the study, all subjects were informed about the experimental procedures and the possible risks and benefits of the study without being informed of its detailed aims to ensure that participants gave equal effort in all the tests. Each subject signed a written informed consent form prior to participation. The experimental protocol was approved by the University Research Ethics Committee of the Faculty of Sciences, Tunis.

\section{Procedures}

Subjects reported to the laboratory on 4 separate occasions (T1, T2, T3, and T4). The first study session (T1) was performed 4 to 5 days before Ramadan. The second (T2) and third (T3) sessions were performed in the middle (days 15 and 16) and the end (days 28 and 29) of Ramadan, respectively. The fourth study session (T4) was performed 3 weeks following Ramadan.

Every study session was conducted over 2 days. On the morning of the first day, anthropometric and fatigue measures were taken and a venous blood sample was collected for the determination of hematological parameters (7). Later that afternoon between 14:00 to 16:00 hours, each subject completed muscle strength and power tests. On the second day, between 14:00 to 16:00 hours, subjects completed a maximal $30-\mathrm{m}$ sprint and a maximal endurance running test. During the Ramadan phase of the study, subjects abstained from eating and drinking according to the religious recommendations. Other than on the first day on each of the study testing sessions when fasting was from 01:00 hours, the period of fasting was from 04:57 to 18:09 hours at the beginning of Ramadan to $05: 19$ to $17: 33$ hours at the end of Ramadan. 


\section{Study Measures}

Subjects reported to the laboratory at 08:00 hours after an overnight rest of 9 to 12 hours. Blood samples were collected from the seated athletes at least 10 hours following their last meal and at least 24 hours after their last training session. During Ramadan, subjects ate before 01:00 hour so that they would be at least 9 hours fasted before the morning blood sample collection. The anthropometric variables of height, body mass (BM), and skinfold thickness were measured, and percentage body fat content and fat free mass were calculated. The anthropometric and hematological methodologies and values have been previously reported in an associated paper (7).

\section{Physical Performance Measures}

All the subjects were familiar with the testing methods used in the study because they were routinely performed as standard scientific follow-up testing during the season. To avoid the influence of changes in circadian rhythms that have previously been reported during Ramadan (31), all tests were conducted at the same time of day (between 14:00 to 16:00 hours) and in the same order under standard environmental conditions $\left(26 \pm 2{ }^{\circ} \mathrm{C}\right.$ and $75 \pm 4 \%$ relative humidity).

The performance measures used in this study were selected because they are common tests of anaerobic power and capacity and aerobic power. Anaerobic power was assessed using a squat jump (SJ), a countermovement jump (CMJ), and a 30 -second repeated jump test followed by a maximal sprint test. Aerobic power was assessed by the multistage fitness test (MSFT) (24). The order of the tests was always: (a) SJ, CMJ, and 30 -second repeated jump test on the first day; and (b) maximal sprint and MSFT on the second day.

\section{Jump Tests}

The SJ, CMJ, and the 30 -second repeated jump tests were assessed on a Quattro Jump portable force plate (Kistler Instrument $\mathrm{AG}$, Switzerland) at a sampling rate of $500 \mathrm{~Hz}$. The subjects completed 3 maximal vertical SJ and CMJ following previously described methods (6). Jumps were measured in triplicate with a 2 -minute rest period between jumps; the greatest jump height and associated peak power was used for analysis.

30-Second Repeated Jump-Test. The repeated jump test was used to assess anaerobic capacity (3) by performing successive maximal jumps (CMJ) on the force platform for a period of 30 seconds (9). Jump height and mechanical work were calculated for each jump during the test. The cumulative flight time and the number of jumps performed formed the basis for the calculations of mechanical power.

Maximal 30-m Sprint Test. After a standardized 10-minute warm-up that included low-intensity running, several acceleration runs, and dynamic stretching, the subjects undertook a sprint running test consisting of 3 maximal sprints of $30 \mathrm{~m}$, timed using electronic photocells (Brower Timing, Draper, Utah, U.S.A.). Times for 5-m and 10-m splits were also taken.
All sprint tests were conducted on the same indoor synthetic track with a 3 -minute active recovery (walking) in between. The fastest $30-\mathrm{m}$ time was selected for analysis.

Multistage Fitness Test. The MSFT was performed 10 minutes after the sprint tests on the same indoor 20-m track according to the methods described by Léger and Gadoury (24). Maximal aerobic velocity $\left(\mathrm{vV}_{\mathrm{O}_{2}} \mathrm{max}, \mathrm{km} / \mathrm{h}\right)$ was taken as the velocity of the final successfully completed shuttle. Maximal oxygen uptake $\left(\dot{\mathrm{V}}_{2} \mathrm{max}\right)$ was estimated from the appropriate regression equation (24).

\section{Physiological Measures}

Heart rate (HR) was recorded at 5-second intervals using heart rate monitors (S810 ${ }^{\mathrm{TM}}$, Polar, Kempele, Finland) during the MSFT. HRmax was taken as the highest HR achieved during the MSFT. Blood lactate concentration was measured 3 -minutes following the 30 -second repeated jump test and the MSFT. Blood samples $(20 \mu \mathrm{L})$ were collected from the subject's earlobe using capillary tubes, and blood-lactate analysis was performed by enzymatic procedures (Microzym-L; SGI, Toulouse, France).

\section{Total Score of Fatigue}

Subjects answered a fatigue abbreviated questionnaire (8 items)(8). The 8 questions focused on the perception of training, sleep, leg pain, infection, concentration, efficacy, anxiety, irritability, and general stress and were assessed on a 7-point Likert scale from very, very good (1 point) to very, very bad ( 7 points). The responses to the questions were summed to obtain the total score of fatigue (TSF). A lower TSF represented a good perception of well-being and a higher score represented an increased perception of fatigue.

\section{Dietary Intake}

Energy intake and fluid consumption were assessed at baseline (pre-Ramadan) during a pre-fasting control week and through and after Ramadan by using a 24-hour recall method (5), which was completed by interview with an experienced dietician. Dietary records were analyzed for energy intake using a customized Microsoft Access database that estimated the subject's food intake according to the food composition tables published by the National Institute of Statistics (Tunisia). The macronutrient and micronutrient dietary estimates of the subjects have been previously reported in an associated paper (7).

\section{Training Load}

To determine whether the subjects' global training load remained consistent through the study, the session rating of perceived exertion (RPE) training score was taken following each session. About 30-minutes after training sessions subjects were asked to rate the global intensity of the entire workout session using the category ratio-10 RPE scale according to the methods described by Foster et al. (16). A daily training load was created by multiplying the training duration (minutes) by the session RPE. The weekly training 
TABLE 1. Performance during the multistage fitness test; maximal velocity tests; heart rate; blood lactate concentration after the MSFT; and fatigue score before, during and after Ramadan. The subject number was 15 for each test.

\begin{tabular}{|c|c|c|c|c|}
\hline Variables & Pre-Ramadan & Mid-Ramadan & End of Ramadan & Post Ramadan \\
\hline \multicolumn{5}{|l|}{ Sprint performance (s) } \\
\hline $5-m$ & $1.23 \pm 0.06$ & $1.22 \pm 0.08$ & $1.19 \pm 0.06$ & $1.21 \pm 0.07$ \\
\hline $10-\mathrm{m}$ & $2.03 \pm 0.08$ & $2.00 \pm 0.13$ & $1.98 \pm 0.07$ & $2.00 \pm 0.09$ \\
\hline 30-m & $4.65 \pm 0.21$ & $4.62 \pm 0.25$ & $4.59 \pm 0.17$ & $4.61 \pm 0.2$ \\
\hline \multicolumn{5}{|l|}{ Aerobic measures } \\
\hline $\mathrm{vV}_{\mathrm{O}_{2}} \max (\mathrm{km} / \mathrm{h})$ & $13.0 \pm 0.6$ & $13.2 \pm 0.5$ & $13.0 \pm 0.6$ & $13.2 \pm 0.6$ \\
\hline \multicolumn{5}{|l|}{ Estimated $\mathrm{V}_{2} \max$} \\
\hline $\mathrm{L} / \mathrm{min}^{-1}$ & $3.61 \pm 0.43$ & $3.54 \pm 0.45$ & $3.53 \pm 0.49$ & $3.68 \pm 0.58$ \\
\hline $\mathrm{mL} / \mathrm{kg}^{-1} / \mathrm{min}^{-1}$ & $53.3 \pm 3.9$ & $54.5 \pm 3.1$ & $53.5 \pm 3.8$ & $54.7 \pm 3.7$ \\
\hline HRmax & $203 \pm 7$ & $202 \pm 9$ & $200 \pm 8$ & $201 \pm 6$ \\
\hline Lactate $\left(\mathrm{mmol} / \mathrm{L}^{-1}\right)$ & $11.3 \pm 1.6$ & $11.1 \pm 2.5$ & $11.0 \pm 2.1$ & $11.0 \pm 1.9$ \\
\hline Total fatigue score & $12 \pm 3$ & $19 \pm 5^{\star}$ & $16 \pm 4^{*}$ & $12 \pm 2$ \\
\hline
\end{tabular}

vن $\mathrm{O}_{2}$ max: velocity associated with $\dot{\mathrm{V}}_{2} \max ; \dot{\mathrm{V}}_{2} \max =$ maximal oxygen uptake; $\mathrm{HRmax}=$ maximal heart rate.

*Values during Ramadan sessions are significantly different $(p<0.05)$ than those before Ramadan.

load was determined by summing the daily training loads for each athlete during each week.

\section{Statistical Analyses}

All data are expressed as mean $\pm S D$. A Friedman's 2-way analysis of variance (ANOVA) for repeated measures was used to determine the differences between the study phases, with each subject serving as their own control $(4,7,15,30,34)$. When a significant $\chi^{2}$ value was achieved, appropriate Wilcoxon post hoc test procedures were used to locate the difference between $\mathrm{T} 1$ (pre-Ramadan measures) and $\mathrm{T} 2$ through T4. Global alpha level control was enforced with the Bonferroni principle; a global 0.05 alpha level was thus distributed evenly among the $\mathrm{k}$ individual comparisons to be done, so that each comparison was tested against a $0.05 / \mathrm{k}$ probability level. According to Sale (32), reproducibility analyses were performed using the method error (ME), calculated as the standard deviation of the mean difference $\left(\mathrm{SD}_{\mathrm{md}}\right)$ between test 1 and 2 divided by the square root of the number of tests performed $(\sqrt{ } \mathrm{n}): \mathrm{ME}=S D_{\mathrm{md}} \times(\sqrt{ } \mathrm{n})^{-1}$. The coefficient of variation $(\mathrm{CV})$, which quantifies the variation between each measurement as a percentage of the joined mean $\left(\left(\mathrm{X}_{1}\right.\right.$ mean $+\mathrm{X}_{2}$ mean $\left.) \times \frac{1}{2}\right)$, was calculated from $\mathrm{ME}$ as follows:

$$
\mathrm{CV}=\mathrm{ME} \times\left[\left(\mathrm{X}_{1} \text { mean }+\mathrm{X}_{2} \text { mean }\right) \times 1 / 2\right]^{-1} .
$$

These calculations were carried out for all outcome measures supplied by the test. The intraclass correlation coefficient (ICC) was also calculated for the same measures. Significance was set at the $p<0.05$ level. Statistical analysis was performed using the SPSS Statistical Package for Social Science (version 13, Chicago, Illinois, USA).

\section{RESULTS}

A consistent training load was maintained throughout the study period. The mean weekly training loads at baseline, during, and after Ramadan were 2095, 2102, and 2119 AU (arbitrary units), respectively. Mean body mass was slightly reduced (1.8\%; $p<0.01)$ by the end of Ramadan mainly as a result of a $0.65 \pm 0.68 \mathrm{~kg}$ decrease in body fat $(p<0.05)$. Mean
Figure 1. Spaghetti graph of mean power kinetics during the 30-s repeat jump test before (T1), during (T2 and T3) and after (T4) Ramadan fasting. The number of subjects was 15 for each test session throughout the study. 
TABLE 2. Performance parameters from the squat jump (SJ), countermovement jump (CMJ), 30-second repeated jump test, and blood lactate ( $\mathrm{La}$ ) levels after the 30 -second repeat jump test during the 4 periods of the study. The subject number was 15 for each test.

\begin{tabular}{lcccc}
\hline \multicolumn{1}{c}{ Variables } & Pre-Ramadan & Mid-Ramadan & End of Ramadan & Post-Ramadan \\
\hline SJ & & & & \\
$\quad$ Height (cm) & $42.0 \pm 3.2$ & $41.5 \pm 3.2$ & $41.8 \pm 3.3$ & $41.8 \pm 3.7$ \\
$\quad$ Force (N/kg) & $23.1 \pm 2.1$ & $22.9 \pm 2.1$ & $22.1 \pm 1.5$ & $22.6 \pm 2.2$ \\
$\quad$ Peak power (W/kg) & $48.5 \pm 3.8$ & $47.5 \pm 4.7$ & $47.7 \pm 3.0$ & $48.2 \pm 3.8$ \\
CMJ & & & & \\
Height (cm) & $45.6 \pm 4.2$ & $44.7 \pm 3.7$ & $45.1 \pm 4.4$ & $44.9 \pm 4.3$ \\
Peak power (W/kg) & $47.8 \pm 3.8$ & $47.8 \pm 4.6$ & $47.6 \pm 3.9$ & $47.3 \pm 3.1$ \\
$\quad$ Ratio SJ height/CMJ height & $0.92 \pm 0.05$ & $0.93 \pm 0.04$ & $0.93 \pm 0.05$ & $0.94 \pm 0.07$ \\
30-second repeat jumping & & & & \\
$\quad$ Average height (cm) & $38.1 \pm 3.6$ & $38.3 \pm 3.9$ & $37.6 \pm 3.6$ & $37.4 \pm 3.6$ \\
$\quad$ Average power (W/kg) & $23.4 \pm 2.3$ & $23.2 \pm 2.4$ & $22.4 \pm 2.3^{*}$ & $23.1 \pm 2.2$ \\
La (mmol/L ${ }^{-1}$ ) & $10.6 \pm 1.1$ & $9.4 \pm 1.5$ & $8.2 \pm 1.6$ & $10.1 \pm 1.6$ \\
\hline
\end{tabular}

*Values during Ramadan sessions are significantly different $(p<0.05)$ than those before Ramadan.

energy intake $(12.9 \mathrm{M} \mathrm{J} /$ day $)$ remained similar throughout the study as did the macronutrient constituents of the diet (7).

\section{Performance, Physiological, and Fatigue Parameters}

Sprint performance remained similar throughout the study (Table 1), with no differences being detected between test sessions for the $30-\mathrm{m}$ sprint times or for the $5-\mathrm{m}$ or $10-\mathrm{m}$ split times. The estimated values for $\dot{\mathrm{V}}_{\mathrm{O}_{2}} \mathrm{max}$ and $\dot{\mathrm{V}}_{2} \mathrm{max}$, determined from the MSFT level reached by the subjects and HRmax reached during the MSFT were also relatively unchanged throughout the study (Table 1). Lactate levels in the circulation approximately 3 minutes after finishing the MSFT were essentially the same at each of the test sessions (Table 1).

The subjective total score of fatigue throughout the study was reasonably low (Table 1); however, it was higher in the middle and end of Ramadan (T2 and T3) in comparison with

TABLE 3. Test-retest reliability of tests.

\begin{tabular}{lccl}
\hline \multicolumn{1}{c}{ Criterion measures } & ICC & $\alpha$ & CV \% \\
\hline SJ & 0.97 & 0.97 & 0.7 \\
CMJ & 0.95 & 0.95 & 0.6 \\
30-second vertical jump test & 0.96 & 0.96 & 0.8 \\
20-m shuttle run test & 0.91 & 0.91 & 2.3 \\
Sprint test & 0.87 & 0.87 & 1.07 \\
\hline
\end{tabular}

$\mathrm{ICC}=$ intraclass correlation coefficient; $\alpha=$ Cronbach's alpha reliability coefficients; $\mathrm{CV}=$ coefficient of variation; $\mathrm{S} J=$ squat jump; $\mathrm{CMJ}=$ countermovement jump. the pre-Ramadan period (T0) $(p=0.001)$. The TSF returned to baseline levels by the third week after Ramadan.

The 30-second repeated jumps test performance had decreased slightly by the end of RIF in comparison with the pre-Ramadan session $(p=0.005)$ but recovered during the period after Ramadan (Figure 1 and Table 2). The performance parameters in the other jump tests did not significantly change during RIF (Table 2). As expected, blood lactate levels determined 3 minutes after the 30 -second repeat jump test were lower than the corresponding lactate concentrations following the MSFT $(p=0.005)$. There was a tendency for the circulating lactate levels to be lower following the repeated jump test during Ramadan than either before or after Ramadan, but no significant differences could be detected (Table 2).

The test-retest intraclass correlation coefficient and the reliability coefficient for all physical tests are presented in Table 3.

\section{Discussion}

The aim of this investigation was to examine the effect of the RIF on the aerobic and anaerobic performances in elite judo athletes who were maintaining their normal training load. The present results demonstrated that the RIF did not adversely affect the overall aerobic and anaerobic performance of the Judokas undertaking intensive physical training. However, there was a reduction in body mass, body fat (7), and the 30 -second jump test performance and an increased perception of fatigue during Ramadan. These findings support the assumption that the metabolic challenges induced by RIF, combined with intense exercise training, have little appreciable effect on the performance of experienced athletes. 
Journal of Strength and Conditioning Research $\mid$ www.nsca-jscr.org

The session RPE method has been shown to be a valid measure of internal training load in a variety of exercise modes $(16,21)$. Moreover, previous studies have used RPE to monitor exercise intensity during competition in elite judo athletes (33). The Judokas in the present study maintained a high training load during the period of the study $(\sim 2100$ AU arbitrary unit) to sustain competitive fitness and muscle mass. The weekly training load measured in this study was similar to the training loads reported during the in-season period in Italian soccer players ( $1900 \mathrm{AU})(21)$ but lower than the loads observed in overreached rugby league players (10).

The main finding of the present study was that there were no significant changes in aerobic performance during the RIF despite a $1.8 \%$ reduction in mean body mass (7). However, there was a significant decrease in the 30 -second jump test performance but not for any other anaerobic test measures during the RIF. A recent study found no significant loss of body mass, aerobic performance, or lactate clearance rates in power-trained athletes during Ramadan (23). In contrast with the present results and those of Karli et al. (23), other studies have shown a reduction in both hand-grip strength and 30-second isometric rowing performance associated with a $5 \%$ body mass loss following a 7-day, self-regulated food and fluid restriction in national-level Judokas $(12,14)$. A possible explanation for the differences in the performance test results between the present study and those of these previous studies is the disparity in body mass losses between the investigations. Additionally, the dietary modifications in the previous studies were deliberately regulated to ensure inadequate energy intake $(12,14)$, whereas in the present study there were no restrictions on either the quantity or type of food that could be consumed between the daily fasts. There was no reduction in the estimated daily energy intake during the RIF $\left(13.1 \pm 2.0 \mathrm{MJ} / \mathrm{d}^{-1}\right)$ compared with that before Ramadan $\left(12.5 \pm 1.2 \mathrm{MJ} / \mathrm{d}^{-1}\right)$ in our athletes $(7)$. Furthermore, it is unlikely that any of the subjects were chronically hypohydrated during the study because estimated mean fluid intake was similar before, during, and after Ramadan and was in excess of $3 \mathrm{~L} / \mathrm{d}^{-1}$ (7). Acute dehydration would, of course, have occurred throughout the hours of daylight each day of Ramadan. It may therefore be significant that the 30-second repeated jump test was the last test carried out in the late afternoon on the days when fast was broken at 01:00 hours, and it was the only test where performance decrements were noted during Ramadan.

The estimated energy intake during the present study was similar to the average baseline data reported for elite judo athletes $(12,14,15)$. Additionally, there was a slight but significant reduction in calculated body fat $(0.65 \pm 0.68 \mathrm{~kg})$ without observable changes in the daily energy intake during RIF (7). These findings are in agreement with recent research examining elite rugby players during Ramadan (4) and suggests that there may be an increased utilization of fat during Ramadan. It is possible that the increased fat oxidation during RIF may assist endurance performance by delaying the onset of fatigue through the sparing of muscle glycogen (18). Previous studies have also shown that fasting prior to exercise may result in greater mobilization of liver glycogen, increased gluconeogenesis, and increased use of free fatty acids for fuel during exercise $(13,17,26)$. It is possible that these metabolic adjustments during fasting may defend against a reduction in performance by maintaining sufficient blood glucose for intense aerobic muscular activity.

The present results demonstrated that the month-long repeated 12 to 13 -hour daily fasts during the Ramadan month did not alter most performance measures. These findings agree with some previous studies that have reported no influence of short-term fasting on maximal exercise performance $(19,23,27)$. For example, McMurray et al. (27) found that $\dot{\mathrm{V}}_{2}$ max was not affected by a negative energy balance following a 7-day fast. In contrast, others have reported that 24-hour fasting can result in a reduction of $\dot{\mathrm{V}}_{2} \mathrm{max}$, increased metabolic acidosis, and a shorter time to exhaustion (17). It is difficult to make direct comparisons between the present results and previous studies because these earlier studies failed to provide detailed information on total energy and macronutrient intake. Additionally, the daily fast in the current study (12-13 hours) was shorter than these previous studies ( $\sim 24$ hours), and therefore it is possible that the duration of the fast period may explain the differences in the results between these investigations. However, 2 other studies, 1 involving Algerian professional soccer players and the other players in an Israeli youth soccer team, found that the Ramadan fast was associated with measurable decreases in physical performance $(29,34)$. In contrast to the present study, the soccer players in both these previous studies reported a decrease in the quality or quantity of their training during Ramadan, which may be the main reason for the measured decrements in performance.

In the present study, both single-effort jump tests (SJ and $\mathrm{CMJ}$ ) and multiple-effort jump test (30-second repeated jump test) were used to assess anaerobic performance. As expected, we observed no significant influence of RIF on SJ and CMJ performances. However, we did observe a small but significant decrease in the 30 -second repeated jump test performance at the end of Ramadan. The lack of change in the single-effort maximal jump tests was expected and agrees with previous research $(19,23)$ that demonstrated no significant reductions in brief, maximal-effort jump tests with either Ramadan or short-term fasting. The significant decrease in the 30-second repeated jump test during RIF in the present study agrees with the findings of Filaire et al. (14), who reported that 7 days of food restriction decreased the mean power output in the 30 -second repeated jump test in elite Judokas. The explanation for the decreased repeated jump test performance in the latter study was that the body mass loss and lower carbohydrate intake caused reductions in muscle-buffering capacity during intense muscular contractions (14). In the present study, however, there was no 
change in the total carbohydrate intake and only a moderate loss of body mass during the RIF (7). Therefore, the physiological mechanisms underlying the decreased 30 second repeated jump test performance in this study remain unknown. Additionally, there was no significant change in peak blood lactate concentration, suggesting that anaerobic glycolysis was not significantly influenced. As a result, we suggest that future studies examine muscle carbohydrate content and its relationship to glycolytic metabolism and performance during the RIF in high-level athletes.

It is well established that hypohydration can reduce physical performance (2). Although previous research has also suggested that chronic dehydration is unlikely during Ramadan, it is probable that moderate levels of hypohydration develop throughout the hours of daylight during RIF, especially in warm weather $(20,25)$. It is likely that some of the body mass loss observed during RIF in the present study can be attributed to acute body water loss. Indeed, a significant $4.4 \pm 6.9 \%$ decrease in plasma volume was detected at the end of Ramadan (7), which may support this suggestion. However, it is more likely that it is the combined effects of a changed diet quality, reduction in meal frequency, and repeated daily dehydration while maintaining the same training schedule throughout the study period that are responsible for the slightly reduced 30-second repeated jump performance and psychological changes observed in the present study.

The increased perception of fatigue reported during RIF is in agreement with previous research that reported an increased sensation of fatigue associated with a hypocaloric dietary intake during 3 days of Ramadan in 750 sedentary Muslims (22). Others have also reported increased perception of fatigue during exercise and at rest, in conjunction with reduced running performance and a lower dietary carbohydrate intake during an 11-day period of intensified training (1). Although the link between the increased perception of fatigue at rest and reduced 30-second repeated jump test performance in the present study is not clear, it is possible that decreased central drive secondary to increased perception of fatigue may be involved in the poorer 30 -second repeated jump test performance.

The results of the present study demonstrated that RIF had little effect on performance during maximal aerobic and anaerobic tests in elite judo athletes. Nevertheless, the RIF did elicit a reduction in the 30 -second repeated jump test performance and increased the athlete's perception of fatigue at the end of the Ramadan month. More research in this area is required to understand the mechanisms and energy pathways that allow athletes to maintain their performance capacities during Ramadan. For example, the ability of athletes to perform repeated-effort activities warrants further investigation. For athletes who are trying to reduce their body mass slightly while trying to maintain their muscle mass and athletic performance, an intermittent fasting model similar to that of the RIF might be more effective than an extended period of restricted energy intake. Further studies are also required to determine the length of time performance can be sustained over such periods of intermittent fasting.

\section{Practical Applications}

The present findings show that experienced athletes who participate in Ramadan can maintain both sufficient energy intake and normal training loads during the RIF. However, it does seem that Muslim athletes may be at risk of losing body mass and experiencing increased feelings of fatigue during the RIF if diet and recovery are not carefully adjusted. These are important considerations for coaches of Judokas, especially because these athletes compete in division set by body mass. It is also suggested that coaches should carefully plan training loads during the RIF to avoid maladaptive training. It is common practice for judo coaches to reduce training demands during the RIF in the belief that this will allow their athletes to cope better with the training while following their religious demands. The present results suggest that highlevel judo athletes can cope with normal training loads during the RIF but that this may increase an athlete's sensation of fatigue, which can be an early sign of overreaching. Therefore we suggest that careful periodization of training, diet, and recovery may be important factors that coaches should consider when training Muslim athletes during the RIF. Another practical application of the present results is that for athletes who are trying to reduce their body mass slightly but maintain their muscle mass and athletic performance, an intermittent-fasting model, similar to that of the RIF, might be more effective than an extended period on an energyrestricted diet. Further studies are also required to determine for how long performance can be sustained over such periods of fasting.

\section{ACKNOWLEDGMenTS}

This study was supported by the Tunisian Ministry of Scientific Research, Technology and Development of Competences, Tunisia. The authors thank the staff of the National Centre of Medicine and Science in Sports and the athletes and the staff of the Tunisian National Judo team. We especially thank Mr. Snoussi Abdelmajid, technical director of the Tunisian Judo Federation; Dr. Mourad Hambli and Dr. Lamia Boussaidi for their assistance in testing; Sghaeir Afef, Zrifi Rym and Amri Hajer for their vital role in lactate sampling and analysis; and Ben Ayed Ikram, Bouzouita Noura, and Hidri Khaoula for their support in the measurement of body composition and dietary collection. Finally, the authors would like to thank Dr. John Leiper for his assistance during the revision of this manuscript and Pr. Edith Filaire for her valuable suggestions.

\section{REFERENCES}

1. Achten, J, Halson, SL, Moseley L, Rayson, MP, Casey, A, and Jeukendrup, AE. Higher dietary carbohydrate content during intensified running training results in better maintenance of performance and mood state. J Appl Physiol 96: 1331-1340, 2004.

2. Barr, SI. Effects of dehydration on exercise performance. Can JAppl Physiol 24: 164-167, 1999. 
3. Bosco, C, Luhtanen, P, and Komi, PV. A simple method for measurement of mechanical power in jumping. Eur J Appl Physiol 50: 273-282, 1983.

4. Bouhlel, E, Salhi, Z, Bouhlel, H, Mdella, S, Amamou, A, Zaouali, M, Mercier, J, Bigard, X, Tabka, Z, Zbidi, A, and Shephard, RJ. Effect of Ramadan fasting on fuel oxidation during exercise in trained male rugby players. Diabetes Metab 32: 617-624, 2006.

5. Burnett, KF, O'Connor, PJ, Kolty, KF, Raglin, JS, and Morgan, WP. Use of three-day food records as estimates of several-day caloric intake during physical training. Med Exerc Nutr Health 3: 185-193, 1994.

6. Canavan, PK and Vescovi, JD. Evaluation of power prediction equations: Peak vertical jumping power in women. Med Sci Sports Exerc 36: 1589-1593, 2004.

7. Chaouachi, A, Chamari, K, Roky, R, Wong, P, Mbazaa, A, Bartagi, Z, and Amri M. Lipid profiles of Judo athletes during Ramadan. Int $J$ Sports Med 29: 282-288, 2008.

8. Chatard, JC, Atlaoui, A, Pichot, V, Gourné, C, Duclos, M, and Guézennec, YC. Training follow up by questionnaire fatigue, hormones and heart rate variability measurements. Science \& Sports 18: 302-304, 2003.

9. Cooke, CB, and Theodorou, A. Evaluation of the validity of a $30 \mathrm{~s}$ vertical jump test. J Sports Sci 16: 30-31, 1998.

10. Coutts, AJ, Reaburn, P, Piva, TJ, and Rowsell, GJ. Monitoring for overreaching in rugby league players. Eur J Appl Physiol 99: 313-324, 2007.

11. Degoutte, F, Jouanel, P, and Filaire, E. Energy demands during a judo match and recovery. Br J Sports Med 37: 245-249, 2003.

12. Degoutte, F, Jouanel, P, Begue, RJ, Colombier, M, Lac, G, Pequignot, JM, and Filaire, E. Food restriction, performance, biochemical, psychological, and endocrine changes in judo athletes. Int J Sports Med 27: 9-18, 2006.

13. El Ati, J, Beji, C, and Danguir, J. Increased fat oxidation during Ramadan fasting in healthy women: An adaptive mechanism for body-weight maintenance. Am J Clin Nutr 62: 302-307, 1995.

14. Filaire, E, Maso, F, Degoutte, F, Jouanel, P, and Lac, G. Food restriction, performance, psychological state and lipid values in judo athletes. Int J Sports Med 22: 454-459, 2001.

15. Finaud, J, Degoutte, F, Scislowski, V, Rouveix, M, Durand, D, and Filaire, E. Competition and food restriction effects on oxidative stress in judo. Int J Sports Med 27: 834-841, 2006.

16. Foster, C, Florhaug JA, Franklin, J, Gottschall, L, Hrovatin, LA, Parker S, Doleshal, P, and Dodge, C. A new approach to monitoring exercise training. J Strength Cond Res 15: 109-115, 2001.

17. Gleeson, M, Greenhaff, PL, and Maughan, RJ. Influence of a $24 \mathrm{~h}$ fast on high intensity cycle exercise performance in man. Eur J Appl Physiol Occup Physiol 57: 653-659, 1988.

18. Horvath, PJ, Eagen, CK, Fisher, NM, Leddy, JJ and Pendergast, DR. The effects of varying dietary fat on performance and metabolism in trained male and female runners. J Am Coll Nutr 19: 52-60, 2000.
19. Houston, ME, Marrin, DA, Green, HJ, and Thomson, JA. The effect of rapid weight loss on physiological functions in wrestlers. Phys Sports Med 9: 73-78, 1981.

20. Husain, R, Duncan, MT, Cheah SH, and Ch'ng SL. Effects of fasting in Ramadan on tropical Asiatic Muslims. Br J Nutr 58: 41-48, 1987.

21. Impellizzeri, FM, Rampinini E, Coutts AJ, Sassi, A, and Marcora, SM. Use of RPE-based training load in soccer. Med Sci Sports Exerc 36: 1042-1047, 2004.

22. Karaağaoğlu, N. and Yücecan, S. Some behavioural changes observed among fasting subjects, their nutritional habits and energy expenditure in Ramadan. Int J Food Sci Nutr 51: 125-134, 2000.

23. Karli, U, Guvenc, A, Aslan, A, Hazir, T, and Acikada, C. Influence of Ramadan fasting on anaerobic performance and recovery following short time high intensity exercise. J Sports Sci Med 6: 490497, 2007.

24. Léger, L and Gadoury, C. Validity of the $20 \mathrm{~m}$ shuttle run test with 1 min stages to predict $\mathrm{V}_{2}$ max in adults. Can J Sport Sci 14: 21-26, 1989.

25. Leiper, JB, Molla, AM. and Molla, AM. Effects on health of fluid restriction during fasting in Ramadan. Eur J Clin Nutr 57: S30-S38, 2003.

26. Loy, SF, Conlee, RK, Winder, WW, Nelson, AG, Arnall, DA, and Fisher, AG. Effects of 24-hour fast on cycling endurance time at two different intensities. J Appl Physiol 61: 654-659, 1986.

27. McMurray, RG, Ben-Ezra, V, Forsythe, WA, and Smith, AT. Responses of endurance-trained subjects to caloric deficits induced by diet or exercise. Med Sci Sports Exerc 17: 574-579, 1985.

28. McMurray, RG, Proctor, CR, and Wilson, WL. Effect of caloric deficit and dietary manipulation on aerobic and anaerobic exercise. Int J Sports Med 12: 167-172, 1991.

29. Meckel, Y, Ismaeel A, and Eliakim A. The effect of the Ramadan fast on physical performance and dietary habits in adolescent soccer players. Eur J Appl Physiol 102: 651-657, 2008.

30. Pulkkinen, WJ. The sport science of elite judo athletes: A review and application for training. Guelph, Ontario, Canada: Pulkinetics Inc., 2001.

31. Roky, R, Houti, I, Moussamih, S, Qotbi, S, and Aadil, N. Physiological and chronobiological changes during Ramadan intermittent fasting. Ann Nutr Metab 48: 296-303, 2004.

32. Sale, DG. Testing strength and power. In: MacDougall, JD, Wenger, $\mathrm{HA}$, and Green, HJ (eds.). Physiological Testing of the High-Performance Athlete. Champaign, IL: Human Kinetics, 1991. pp. 21-106.

33. Serrano, MA, Salvador, A, Gonzalez-Bono, EG, Sanchis, C, and Suay F. Relationships between recall of perceived exertion and blood lactate concentration in a judo competition. Perceptual and Motor Skills 92: 1139-1148, 2001.

34. Zerguini, Y, Kirkendall, D, Junge, A, and Dvorak, J. Impact of Ramadan on physical performance in professional soccer players. Br J Sports Med 41: 398-400, 2007. 